\title{
LOS COLORES DE LA PATRIA. SÍMBOLOS NACIONALES EN LA ESPAÑA CONTEMPORÁNEA
}

Por Javier Moreno Luzón y Xosé M. Núñez SeiJas. Madrid: Editorial Tecnos, 2017, 452 páginas. ISBN: 978-84-309-7114-5

La obra que presentamos a los lectores de Historia y Memoria de la Educación está escrita por dos de los más conocidos historiadores del nacionalismo español, Javier Moreno Luzón y Xosé Manuel Núñez Seijas. En ella se realiza un recorrido, que arranca en 1785 y llega hasta 2014, de los símbolos «nacionales» por antonomasia, las banderas y los himnos. En el prólogo del libro, Anne-Marie Thiesse, la conocida autora de esa magna obra sobre la creación de las identidades nacionales en Europa entre los siglos XVIII y xx (ed. du Seuil, 1999), nos recuerda que "himnos y banderas sirven para identificar un país, en el espacio nacional e internacional, de modo preciso y estable» (p. 10). En ellos se sintetizan y condensan las representaciones de esas «comunidades imaginadas» que son las naciones, según la conocida definición acuñada por Benedict Anderson en 1983. ${ }^{1}$ Como es bien sabido, este historiador rompió con los planteamientos clásicos del nacionalismo esencialista, que defendía la existencia de las naciones como entes naturales y casi eternos, y las presentó como construcciones modernas y creadas cultural y socialmente. ${ }^{2}$ En ese proceso de creación es en el que ocupa un papel central la representación simbólica que cada país hace de sí mismo, y que va cambiando en función de los enfrentamientos y de los compromisos políticos, por lo que es habitual contemplar rupturas en la simbología nacional aunque, curiosamente, hay una tendencia al mantenimiento de estos símbolos,

\footnotetext{
${ }^{1}$ Benedict Anderson, Imagined Communities. Reflections on the Origin and Spread of Nationalism (London: Verso, 1983). Traducción al castellano de Eduardo L. Suárez, Comunidades Imaginadas. Reflexiones sobre el Origen y la Difusión del Nacionalismo (México: Fondo de Cultura Económica, 1993).

${ }^{2}$ Craig Calhoun, «La importancia de Comunidades Imaginadas y de Benedict Anderson», Debats 130, no. 1 (2016): 11-17.
} 
como forma de expresar la continuidad histórica que se pretende atribuir a la comunidad nacional.

Javier Moreno y Xosé Manuel Núñez parten de esa premisa inicial, de la importancia que tienen los símbolos para configurar las identidades nacionales, coadyuvando «de manera eficaz a la tarea de nacionalizar las poblaciones y permiten legitimar regímenes y movimientos políticos nacionalistas, dotándoles de un arsenal de imágenes fácilmente reconocibles» (p. 18). Sin embargo, la historia de los emblemas nacionales es un tema que ha interesado poco a los académicos, y mucho menos a los españoles, salvo el trabajo pionero y rompedor de Carlos Serrano, ${ }^{3}$ que inspiró a toda una generación de historiadores culturales. De ahí la importancia de este libro, que pretende comprender la evolución e importancia de los dos emblemas fundamentales de la nación, bandera e himno, desde una triple perspectiva. En primer lugar, «la de sus usos oficiales», como representación del Estado y como instrumento de nacionalización a través de diferentes agentes como el ejército, la escuela, la Iglesia católica o los medios de comunicación. En segundo lugar, «la de los usos sociales complementarios», muy cercanos al nacionalismo banal de Billig, ${ }^{4}$ que transformaron estos símbolos y les dotaron de significados diferentes. Y, en tercer lugar, «la de las tensiones y choques políticos que se han desarrollado en torno a los símbolos» (p. 23), tanto entre las diferentes tendencias del nacionalismo español como entre el españolismo y los movimientos nacionalistas «subestatales». Con este término los autores denominan a los nacionalismos catalán, gallego y vasco, obviando el manido calificativo de «periféricos» tan en boga en la historiografía pasada y reciente, cuyas connotaciones semánticas estimulan un imaginario de confrontación y antítesis.

Esta obra se presenta dividida en ocho capítulos. El primero, «De símbolos oficiales a símbolos nacionales (1785-1898)», relata la invención de la bandera roja y amarilla en 1785 y sus primeras referencias como «bandera nacional»; y los más confusos orígenes de la Marcha Granadera, conocida al menos desde 1836 como Marcha Real. Uno y otro símbolo surgieron como emblemas militares y de claras resonancias monárqui-

\footnotetext{
${ }^{3}$ Carlos Serrano, El nacimiento de Carmen. Símbolos, mitos, nación (Madrid: Taurus, 1999).

${ }^{4}$ Michael Billig, Banal Nationalism (London: Sage, 1995). Traducción al castellano de Ricardo García Pérez, Nacionalismo Banal (Madrid: Capitán Swing, 2014).
} 
cas, frente al carácter revolucionario que tuvieron los símbolos nacionales de otros países como Estados Unidos o Francia. El Trienio Liberal trajo el Himno de Riego que, en palabras de los autores, «se convirtió no sólo en una de las canciones patrióticas más famosas, sino también en lo más parecido a un himno nacional que tuvo España a lo largo de todo el siglo XIX» (p. 37). Y también recuperó el color morado, reminiscencia comunera, como símbolo de las tendencias progresistas, y posteriormente republicanas, a lo largo de toda la época contemporánea.

El segundo capítulo, «Regeneración simbólica (1893-1917)», se centra en los afanes de españolización desplegados por las élites del país a partir de la crisis de 1898 y del riesgo de desmembración nacional. La bandera, que ya se había convertido en las décadas anteriores en un símbolo nacional bastante visible, se popularizó aún más por su presencia habitual en contextos banales, como las corridas de toros o los uniformes de los jugadores del recién nacido Madrid Foot-ball Club. La Marcha Real, sin embargo, se refugió en las ceremonias monárquicas y religiosas. Y, mientras tanto, el movimiento catalanista consensuó la bandera nacional de Cataluña, la senyera, y el himno Els Segadors, según la versión publicada, precisamente, en 1898. En el País Vasco los hermanos Arana diseñaron e izaron la ikurriña en 1894 y pusieron letra a una melodía folklórica para que sirviera como himno, aunque la mayoría de la población prefirió el Gernikako Arbola. Y los círculos regionalistas gallegos adoptaron su bandera blanca y azul y el himno Os Pinos. Esta encrucijada de amenaza de los diferentes nacionalismos explica la creciente preocupación del Estado por españolizar a las masas, descubriendo así un nuevo y poderoso instrumento de nacionalización: la escuela. En este punto los autores, siguiendo una línea de investigación que ya tiene una cierta tradición en nuestro país, ${ }^{5}$ describen todos los proyectos liberales para introducir la

\footnotetext{
${ }^{5}$ María del Mar del Pozo Andrés y Jacques F. A. Braster, «The Rebirth of the "Spanish Race": The State, Nationalism and Education in Spain, 1875-1931", European History Quarterly 29, no. 1 (1999): 75-108; Carolyn P. Boyd, Historia Patria. Política, historia e identidad nacional en España: 18751975 (Barcelona: Pomares-Corredor, 2000); María del Mar del Pozo Andrés, Currículum e Identidad Nacional. Regeneracionismos, nacionalismos y escuela pública (1890-1939) (Madrid: Biblioteca Nueva, 2000); María del Mar del Pozo Andrés y Antonio Francisco Canales Serrano, «Educación, ciudadanía e identidad nacional en la España contemporánea», en Nuevos horizontes del pasado. Culturas políticas, identidades y formas de representación, eds. Ángeles Barrio Alonso, Jorge de Hoyos Puente y Rebeca Saavedra Arias (Santander: PUbliCan, 2011), 233-250; Alejandro Mayordomo Pérez y Juan Manuel Fernández-Soria, «Educación, cultura política, causa pública. Una lectura histórica», Revista Española de Pedagogía Lxxi, no. 256 (2013): 423-440; María del Mar del Pozo Andrés, «Colgar
} 
bandera en las escuelas públicas — denominadas «nacionales» a partir de 1912 - y apuntan algunas de las conmemoraciones escolares de carácter conservador, como la Fiesta del Árbol, en las que la enseña nacional también acabó ocupando un puesto central.

El tercer capítulo, «Símbolos de la monarquía conservadora (19171930)», aborda las estrategias de la reacción conservadora ante los desafíos de los crecientes nacionalismos subestatales y ante el desvío de la sociedad civil como consecuencia de las catastróficas campañas de Marruecos. ${ }^{6}$ Los autores narran de forma amena las «guerras de símbolos» que se vivieron por diferentes partes de la península y que alcanzaron hasta a un jovencísimo Salvador Dalí, arrestado por quemar una bandera rojigualda; el rechazo claro a la Marcha Real, que era recibida con abucheos hasta en Madrid o en Valladolid; y las reacciones en Barcelona de los miembros de la vocinglera Liga Patriótica Española, que «colgaban enormes banderas españolas en sus balcones» y coreaban, "no se sabe con qué letra, la Marcha Real» (p. 153). El cancionero patriótico que surgió como consecuencia de la guerra de Marruecos, con tonadillas procedentes de zarzuelas y pasodobles, como la famosa La banderita, que ligaba el color rojo con los vinos de Jerez y Rioja, despertaron la nostalgia de amplios sectores de la sociedad y contribuyeron a construir un imaginario nacionalista espontáneo. Ese nacionalismo español, de carácter cada vez más conservador, se fundió con la Corona y con la figura de Alfonso XIII, al que se identificó cada vez más con los símbolos patrióticos de corte españolista. No es de extrañar, entonces, que el rey impulsase la

\footnotetext{
a España de las paredes: Imágenes y construcción de la identidad nacional desde la escuela (18751975)», en Narrar historias de la educación. Crisol y alquimia de un oficio, ed. María Esther Aguirre Lora (México: Bonilla Artigas Editores y UNAM, 2015), 37-78; María del Mar del Pozo Andrés, "Hanging Spain on the walls: Images and building of national identity from the schools (1875-1975)», en Conditioned Identities. Wished-for and Unwished-for Identities, ed. Flocel Sabaté (Berna: Peter Lang, 2015), 175-202, y Javier Moreno Luzón, «“'Salve, Bandera de mi Patria, Salve!”. Los símbolos nacionales en la escuela española (1890-1920)». Ponencia presentada en el 48th Annual Meeting de la Association for Spanish and Portuguese Historical Studies, celebrado en New York University del 16 al 18 de marzo de 2017.

${ }^{6}$ Algunos de los trabajos ya clásicos sobre la vertiente escolar de este impulso nacionalizador son Alejandro Quiroga Fernández de Soto, «Maestros, espías y lentejas. Educación y nacionalización de masas durante la Dictadura de Primo de Rivera», en Construir España. Nacionalismo español y procesos de nacionalización, ed. Javier Moreno Luzón (Madrid: Centro de Estudios Políticos y Constitucionales, 2007), 183-205, y Alejandro Quiroga Fernández de Soto, «Educación para la ciudadanía autoritaria. La nacionalización de los jóvenes en la Dictadura de Primo de Rivera», Historia de la Educación. Revista Interuniversitaria 27 (2008): 87-104.
} 
primera versión con letra de la Marcha Real, que, por otra parte, se convirtió en el símbolo más denostado del Estado, especialmente durante la etapa de la dictadura primorriverista. Ante el celo antiseparatista exhibido por Primo de Rivera, un público de miles de aficionados pitó la Marcha Real en junio de 1925, en el campo del Fútbol Club Barcelona, en el que fue quizás el primer ejemplo de utilización del deporte como medio de exaltación de la identidad nacional. Y, como concluyen los autores, el ambicioso programa de españolización de Primo de Rivera, que abarcó todos los espacios visibles, desde el cuartel hasta la escuela, tuvo el efecto contraproducente de extender entre la sociedad civil una identificación de los símbolos estatales «con una sola versión del españolismo: militarista, católica, autoritaria y monárquica» (p. 185).

Por eso no es de extrañar que el republicanismo exhibiese desde el final de los años diez sus propios símbolos, la bandera tricolor y el Himno de Riego, por más que, en estos años, se consideraban emblemas del pasado. A su apropiación como símbolos del nuevo Estado republicano se dedica el capítulo 4 de la obra, «Los dilemas simbólicos de la República (1930-1936)». En él se describe el papel de las instituciones locales en la consagración de la bandera tricolor, al izarla en muchos Ayuntamientos de España en las primeras horas de ese 14 de abril, un hecho que adquirió carta legal pocos días después, con un decreto que legitimó el estandarte republicano como símbolo de «una nación definida como comunidad política de ciudadanos» (p. 199). La escuela se convirtió, en estos momentos, en un espacio importante de nacionalización estatal, como ya han señalado varios autores. ${ }^{7}$ Sin embargo, con el himno no hubo acuerdo entre los diferentes sectores del gobierno republicano-socialista, aunque el de Riego fue el más ejecutado en las conmemoraciones del 14 de abril y en los eventos educativos.

\footnotetext{
${ }^{7}$ Sandie Holguín, República de Ciudadanos. Cultura e identidad nacional en la España republicana (Barcelona: Crítica, 2003); María del Mar del Pozo Andrés, «La construcción de la identidad nacional desde la escuela: El modelo republicano de educación para la ciudadanía», en Construir España. Nacionalismo español y procesos de nacionalización, ed. Javier Moreno Luzón (Madrid: Centro de Estudios Políticos y Constitucionales, 2007), 207-232; María del Mar del Pozo Andrés, «Educación para la ciudadanía democrática en la Segunda República: Un intento de construcción de la identidad nacional desde la escuela», Historia de la Educación. Revista Interuniversitaria 27 (2008): 105-135; Alejandro Mayordomo y Juan Manuel Fernández Soria, Patriotas y ciudadanos. El aprendizaje cívico y el proyecto de España (Valencia: Tirant lo Blanch, 2008), y María del Mar del Pozo Andrés, «La construcción y la destrucción de la nación cívica desde la escuela en la Segunda República», Hispania Nova. Revista de Historia Contemporánea 11 (2013). http://hispanianova.rediris.es
} 
El quinto capítulo, «Símbolos en guerra (1936-1939)» aborda los conflictos por los emblemas de la nación que se vivieron en las dos zonas. En la republicana la bandera tricolor coexistió con otros muchos símbolos socialistas y comunistas, si bien el gobierno redobló sus esfuerzos para identificarla con la España libre. Al mismo tiempo, el Himno de Riego "cayó en un progresivo desuso» (p. 237), superado por el empuje de los cantos partidistas socialistas, comunistas y anarquistas. En el bando sublevado se siguió enarbolando en los primeros momentos la bandera republicana, si bien la vuelta a la bicolor «estaba pactada, aunque en términos poco claros» (p. 243). El esfuerzo del general Franco se orientó a desterrar de la mente de sus partidarios la identificación de este símbolo con la monarquía para asociarla a la idea de la España eterna y católica. Mientras tanto, los falangistas exhibían su bandera rojinegra y aspiraban a que se convirtiese en la enseña de la nación entera. Un fenómeno similar, aunque quizás más virulento, se produjo con los himnos, pues los de carácter guerrero - desde el Cara al Sol hasta el de los legionarios-y los pasodobles tradicionales, se impusieron a la Marcha Real, la cual, además, tenía un nombre muy inadecuado para los nuevos tiempos. Por eso, no es de extrañar la obsesión de Franco por buscar un himno nacional que despertase el patriotismo emocional de los españoles, así como la imposibilidad de encontrar ninguno, por lo que hubo de recurrirse de nuevo a la Marcha Real, de la que se suprimieron los antecedentes monárquicos y se construyó una vinculación simbólica con la figura del dictador. Franco personalmente encargó al escritor José María Pemán que remozase la letra que ya había compuesto en 1928, dándole un mayor tono fascista para contentar a los falangistas, si bien esta guerra de los himnos persistió durante los años de la Guerra Civil y encontró en la escuela uno de sus escenarios. ${ }^{8}$

La imposición de los símbolos patrióticos durante la etapa franquista es el tema central del capítulo 6, «Paradojas de la nacionalización autoritaria (1939-1975)», y también es la etapa en la que más se ha trabajado desde la historia de la educación, que ha analizado especialmente

\footnotetext{
${ }^{8}$ Alejandro Mayordomo y Juan Manuel Fernández-Soria, Vencer es convencer. Educación y política: España, 1935-1945 (València: Universitat de València, 1993), y Lara Campos Pérez, Los relatos de la nación. Iconografía de la idea de España en los manuales escolares (1931-1983) (Madrid: Centro de Estudios Políticos y Constitucionales, 2010).
} 
la construcción curricular del discurso nacionalista en la manualística escolar de estos años. ${ }^{9}$ Los autores explican el rápido proceso de identificación de los símbolos nacionales con Franco y su apropiación por el franquismo, pero también las tensiones creadas entre las diferentes familias políticas y las pugnas entre la simbología religiosa y la nacionalista, conflictos en los que la escuela actuó como caja de resonancia, si bien hay que buscar sus rastros en signos tan sutiles como la ubicación y composición de los diferentes emblemas en las paredes del aula. ${ }^{10} \mathrm{El}$ escaso entusiasmo de los falangistas por el himno oficial de España hizo que el Frente de Juventudes y la Sección Femenina potenciasen indisimuladamente el Cara al Sol como canto nacional. ${ }^{11}$ Los autores apuntan una realidad poco conocida pero también señalada recientemente desde la historiografía educativa, y es la de que no todos los colegios religiosos y, ni siquiera todas las escuelas públicas, siguieron las directrices políticas sobre el culto a los símbolos nacionales —que, por otra parte, empezaría a decaer a lo largo de la década de 1950 — , mientras que la veneración hacia la simbología católica fue unánime. ${ }^{12}$ Sin embargo, estudios recientes basados en fuentes orales también nos hablan de la eficacia de los rituales nacionalistas en torno a banderas e himnos para despertar emociones en algunos escolares. ${ }^{13}$

\footnotetext{
${ }^{9}$ Sin embargo, la construcción y transmisión de los símbolos nacionales en la escuela franquista es un tema que ha interesado menos a los historiadores de la educación. Algunas de las obras citadas con anterioridad han abordado esta cuestión, que también aparece tangencialmente, en los siguientes artículos: Ana María Badanelli Rubio y María del Mar del Pozo Andrés, «Desde la MadrePatria española al Estado de las Autonomías: La idea de España en los manuales escolares (19002007)», Historia de la Educación. Revista Interuniversitaria 27 (2008): 397-432; Ana Badanelli Rubio y Kira Mahamud Angulo, «Entre la ruptura y la continuidad de esquemas socioemocionales en los libros de lectura de la escuela primaria en el tardofranquismo (1959-1975)», Historia y Memoria de la Educación 2 (2015): 125-160, y Kira Mahamud Angulo, «Emotional indoctrination through sentimental narrative in Spanish primary education textbooks during the Franco dictatorship (19391959)», History of Education 45, no. 5 (2016): 653-678.

${ }^{10}$ Pozo, «Colgar a España de las paredes», 37-78.

${ }^{11}$ José Ignacio Cruz Orozco, El yunque azul. Frente de Juventudes y sistema educativo: Razones de un fracaso (Madrid: Alianza Editorial, 2001).

${ }^{12}$ Pozo, «Hanging Spain on the walls», 175-202, y María del Mar del Pozo Andrés y Teresa Rabazas Romero, «Políticas educativas y prácticas escolares: La aplicación de la Ley de Enseñanza Primaria de 1945 en las aulas», Bordón. Revista de Pedagogía 65, no. 4 (2013): 126-127.

${ }^{13}$ Carlos Fuertes Muñoz, «La nación vivida. Balance y propuestas para una historia social de la identidad nacional española bajo el franquismo», en La nación de los españoles. Discursos y prácticas del nacionalismo español en la época contemporánea, eds. Ismael Saz y Ferran Archilés (València: Universitat de València, 2012), 287-288.
} 
Los capítulos 7 y 8, titulados «Símbolos del consenso (1975-1985)» y "Prácticas simbólicas en conflicto (1981-2014)», nos remiten a nuestro pasado reciente, historiando algunos hechos que aún están presentes en la memoria de aquellos españoles mayores de cincuenta años, como el proceso que siguieron los partidos de izquierdas al final de la década de los setenta para renunciar a los símbolos republicanos y aceptar los de la monarquía constitucional, al mismo tiempo que los partidos ultraderechistas se apropiaban de todos los símbolos nacionales. Después del golpe de Estado de Tejero se «inventó» la bandera constitucional y se inició una política para convertirla en símbolo de la nación, mientras que, a partir de mediados de los años ochenta, «coincidiendo con la construcción del Estado de las autonomías» (p. 383), proliferaron los estandartes de las Comunidades Autónomas que eran utilizados en muchas ocasiones «como emblema complementario o metáfora de la españolidad» (p. 384). Los autores se detienen especialmente en el proyecto de renacionalización española iniciado por el primer gobierno aznarista en 1996, y con las medidas desplegadas por éste para historiar los orígenes de la bandera, revalorizar el himno y visibilizar ambos en la sociedad española. Este empeño tuvo, en opinión de los autores, una consecuencia paralela, el resurgimiento de la enseña tricolor republicana, cuya popularización se debió a un conjunto de factores, entre ellos, la pérdida de prestigio de la monarquía parlamentaria y el crecimiento de los movimientos en favor de la recuperación de la memoria histórica. La escuela no está presente en ningún momento de este proceso, no parece que haya tenido ningún papel en la construcción de la identidad nacional a partir de 1980. Este tema tampoco ha despertado la curiosidad de los investigadores, salvo en el aspecto específico de la enseñanza de la historia. Quizás merecería la pena que, como historiadores de la educación, reflexionásemos sobre el significado de este desinterés.

Los autores concluyen que «los símbolos mantienen su peso en la vida pública, como vehículos de nacionalización [...]. Su capacidad de catalizar y condensar emociones, cruciales para la difusión y reproducción social de los nacionalismos, sigue fuera de toda duda» (p. 425). Esta obra muestra cómo, en determinados momentos históricos, la escuela tuvo un papel importante en la construcción, difusión y apropiación de estos símbolos; también sabemos que este papel dependió en mayor medida del entusiasmo de los docentes que de las normativas impuestas por 
la política educativa o de los discursos sociales dominantes. Conocer e interpretar el papel que la escuela ha jugado en estas últimas décadas en la construcción de las diferentes identidades nacionales que hoy coexisten en nuestro país, y para divulgar sus representaciones simbólicas, es un reto que deberíamos recoger los historiadores de la educación. Espero y deseo que un libro tan interesante y exhaustivo como el de Javier Moreno Luzón y Xosé Manuel Núñez Seijas nos sirva de estímulo y acicate para emprender esta tarea.

María del Mar del Pozo Andrés Universidad de Alcalá mar.pozo@uah.es 